\title{
Sentidos e experiências relatados por mulheres em relacionamentos não monogâmicos
}

\section{Meanings and experiences reported by women in non-monogamous relationships}

\author{
Ana Clara Rubin Corá1, Rafael De Tilio ${ }^{2}$
}

\section{Resumo}

Nas últimas décadas uma das principais transformações sociais e sexuais foi o questionamento do ideal de relacionamento afetivo e sexual baseado na monogamia, sendo a não monogamia uma das suas principais manifestações. O objetivo desta pesquisa foi compreender relatos de mulheres que vivenciam ou vivenciaram relacionamentos amorosos e sexuais não monogâmicos. Dez mulheres com idades entre 20 e 34 anos que vivenciam ou vivenciaram ao menos um relacionamento não monogâmico foram entrevistadas. Seus relatos foram agrupados em três categorias a partir de uma análise de conteúdo temática. Os principais resultados destacaram: as transformações das intimidades no que se refere à liberdade afetiva e sexual; a multiplicidade de parceiros episódicos ou constantes; os questionamentos das opressões de gênero e de orientações sexuais heteronormativas e monogâmicas; a importância do diálogo como estratégia de resolução dos conflitos e de enfrentamento do ciúme. Todos esses resultados apontam para as transformações das intimidades contemporâneas que promovem a visibilidade de grupos, comunidades e sujeitos outrora reprimidos. É necessária a continuidade do debate visando alterar as opressões entre os gêneros ainda persistentes na sociedade brasileira.

Palavras-chave: Amor; Poliamor; Gênero; Relacionamentos abertos.

\begin{abstract}
In the last decades, one of the main social, affective and sexual transformation has been the questioning of the ideal of affectionate and sexual relationships based on monogamy, with non-monogamy being one of its main manifestations. The objective of this research was to understand the reports of women who experience or have experienced non-monogamous love and sexual relationships. Ten women between 20 and 34 years-old who experience or have experienced at least one non-monogamous relationship were interviewed. Their reports were grouped into three categories based on a thematic content analysis. The main results highlighted: the transformations of intimacies with regard to affective and sexual freedom; the multiplicity of episodic or long-lasting partners; the questioning of the gender oppressions and the heteronormative and monogamous sexual orientations; the importance of dialogue as a strategy for resolving conflicts and facing jealousy. The results point to the transformations of contemporary intimacies that promote the visibility of groups, communities and subjects that were once repressed. It is necessary to continue the debate to altering the gender oppression that still persists in Brazilian society.
\end{abstract}

Keywords: Love; Polyamory; Gender; Open relationship.

\footnotetext{
${ }^{1}$ Graduanda em Psicologia pela Universidade Federal do Triângulo Mineiro (UFTM), Uberaba, Minas Gerais, Brasil. E-mail: anarubincora@gmail.com

${ }^{2}$ Doutorado em Ciências pela Universidade de São Paulo (USP), São Paulo, São Paulo, Brasil. Professor da Universidade Federal do Triângulo Mineiro, Uberaba, Minas Gerais, Brasil.E-mail: rafael.tilio@uftm.edu.br
} 
Ao longo da história as mulheres foram assumindo diferentes papéis e funções na sociedade, especialmente no que se refere à divisão social e sexual do trabalho e às movimentações nas dinâmicas entre os espaços públicos e privados. De modo resumido e sem querer esgotar o tema, segundo Muller e Besing (2018), a trajetória da feminilidade e das mulheres nas sociedades ocidentais de tradição europeia cristã - incluindo, portanto, parte significativa do processo civilizatório brasileiro poderia ser representada pelo embate entre as tentativas de dominação masculina e submissão feminina e a busca pela liberdade e pela autonomia afetiva e sexual das mulheres diante dos homens. Apesar das inúmeras tentativas - algumas exitosas - de resistências à dominação masculina, Federici (2017) e Iop (2009) argumentam que essa dominação resistiu e ainda resiste, da qual decorreram muitas consequências e, dentre estas, as estratégias de imposição de um modelo de relacionamento amoroso e sexual de caráter monogâmico visando o controle da circulação e do uso dos corpos das mulheres.

Ainda segundo Muller e Besing (2018), apesar de ser possível traçar uma longa duração destas estratégias de dominação, elas obtiveram destaque desde o final da Idade Moderna (séculos XV-XVIII) até o início da Idade Contemporânea (séculos XVIII e seguintes) com a Revolução Industrial europeia e com a consolidação do sistema de produção capitalista, ficando evidentes os tradicionalismos de/ entre os gêneros que delegam aos homens e às mulheres funções distintas, reservando aos homens os privilégios e a ocupação do espaço público e às mulheres os desprivilégios e a ocupação do espaço privado/doméstico. Neste contexto Federici (2017) argumenta que as mulheres foram prioritariamente situadas como responsáveis pela reprodução biológica e social - as mães geratrizes e cuidadoras da prole, dos necessitados e do espaço doméstico - em um sistema calcado na desigualdade entre os gêneros, fundamentado no incentivo ao casamento/ relacionamento monogâmico heterossexual. Por isso, as mulheres foram consideradas força de trabalho doméstico, cujos afetos e sexualidades deveriam servir aos interesses dos homens (IOP, 2009).
A replicação dessa dominação pode ser compreendida também a partir da perspectiva das relações de trabalho: os homens se ocupavam das tarefas nos espaços públicos garantindo a renda e o sustento familiar enquanto que as mulheres cuidavam dos afazeres domésticos na própria casa ou na casa de outrem - isto é, sua inserção no mundo do trabalho transitava e se limitava àquelas atividades consideradas próprias do seu sexo/gênero, ou seja, os cuidados. Neste cenário as mulheres continuaram quase que exclusivamente restritas às atividades do âmbito doméstico, praticamente excluídas do mercado formal e remunerado de trabalho - e quando trabalhavam fora do ambiente doméstico suas condições de trabalho eram informais e precárias e seu salário e valorização social eram menores quando comparadas aos homens, reforçando sua dependência (FEDERICI, 2017; IOP, 2009).

Em suma, segundo Foucault (2020), foi a partir da dominação promovida e sustentada pelo casamento monogâmico e heterossexual, da delegação das mulheres ao papel de mães e da exploração do trabalho doméstico feminino mal ou não remunerado que decorreu a consolidação de um sistema de vigilância e de controle dos corpos e das subjetividades das mulheres - há de se considerar que o controle dos corpos e dos afetos femininos foi uma das principais táticas do dispositivo da sexualidade visando controlar as mulheres. Por isso, o casamento monogâmico e heterossexual foi considerado na ocidentalidade pedra-de-toque deste sistema de dominação com características patriarcais (ILLOUZ, 2012). Das mulheres transformadas em patrimônios e dependentes econômica e afetivamente dos homens decorreu um modelo de feminilidade considerado ideal: esposa passiva, obediente e moral e sexualmente casta (FEDERICI, 2017; KNIBIEHLER, 2016; PINSKY, 2016).

Por isso, os relacionamentos monogâmicos e estáveis atuavam como meios de assegurar os direitos dos homens sobre a propriedade - incluindo as mulheres - visto que juntamente com o casamento formalizado pretendiam garantir que sua parceira teria relações sexuais somente consigo e, dessa forma, seu patrimônio estaria reservado aos 
herdeiros legítimos - garantindo a perpetuação dos privilégios. O casamento monogâmico e heterossexual na modernidade e na contemporaneidade, dessa forma, teve como finalidade precípua não a satisfação dos interesses particulares dos parceiros amorosos, mas sim perpetuar o poder masculino na sociedade a partir do controle do corpo feminino (KNIBIEHLER, 2016).

Como referido, esse sistema de dominação patriarcal e patrimonialista pautado na desigualdade entre os gêneros marcou profundamente $o$ processo civilizatório brasileiro desde a Colônia (séculos XVI-XIX) até a República (final do século XIX e décadas seguintes). De maneira sucinta e sem a pretensão de fornecer um relato exaustivo ou completo sobre a temática ${ }^{3}$, Saffioti (2013) argumenta que naquela dinâmica a função da mulher era ser propriedade privada dos homens brancos tanto no trabalho (doméstico e não remunerado, tanto para as mulheres brancas como para as não brancas) quanto na sexualidade (satisfação sexual masculina, seja nos esquemas de procriação e geração de descendentes com as mulheres brancas, seja nas violências sexuais impetradas contra as mulheres brancas ou não brancas). Assim, segundo Priore (2006) o modelo familiar considerado ideal e socialmente valorizado a partir da perspectiva europeia branca e cristã foi aquele promovido pelo casamento monogâmico heterossexual com rígida distinção de papéis sociais e sexuais entre os gêneros. Porém, segundo Lévi-Strauss (1980) esse arranjo monogâmico resulta de aspectos históricos, culturais e de relações de poder mais do que dos aspectos biológicos e, portanto, segundo Illouz (2012; 2019) esses processos de naturalização e de normatização revelam a possibilidade de sua coexistência com modelos concorrentes - porém, menos visíveis ou incentivados - de famílias e de satisfações afetivas e sexuais não monogâmicas.
Assim, conforme destacam Illouz (2012), Muller e Besing (2018) e Perez e Palma (2018), mediante as alterações nos papéis das mulheres nas famílias e nos relacionamentos ao longo dos séculos o sentimento de amor no mundo ocidental, de tradição europeia cristã, também sofreu diversas modificações em seus sentidos e significados, apesar de suas recorrentes tentativas de estabilização por parte de grupos de interesses específicos. Também sobre o tema não há a pretensão de se estabelecer uma cronologia exaustiva destas modificações e permanências, mas sim destacar que o sentimento de amor na contemporaneidade obteve relevância primeiro como amor romântico, imiscuindo aspectos como sucesso e satisfação pessoal, ascese moral, contenção, controle e constância - contraposto ao amor paixão, volúvel e fugaz que poderia ser obtido principalmente por meio dos relacionamentos (casamentos) monogâmicos estáveis e indissolúveis. Considerado fundamento das uniões estáveis e duradouras das famílias nucleares burguesas, o amor romântico foi equiparado ao padrão-ouro dos sentimentos e da satisfação pessoal e, dessa forma, qualquer diversificação ou variação nas modalidades de apresentação deste sentimento, ou mesmo dos modelos considerados ideais de relacionamentos (monogamia), foram desvalorizados e combatidos.

Para Giddens (1993), essa idealização do sentimento de amor romântico decorrente da longa tradição europeia cristã começou a ser questionada com contundência principalmente a partir da denominada revolução sexual ocorrida na segunda metade do século XX. Segundo o autor, a utilização em larga escala de contraceptivos industrializados pelas populações ocidentais e urbanas promoveu a progressiva desvinculação da satisfação sexual das funções reprodutivas, pressionando por modificações tanto nas formas consagradas e

\footnotetext{
${ }^{3}$ Com isso queremos destacar que a tradição europeia cristã que enfatiza os relacionamentos monogâmicos, heterossexuais, o duplo padrão/moral sexual e o amor romântico para a formação das famílias é somente uma das possíveis, mas não a única, tradições existentes. Todavia, foi esta a considerada ideal no Brasil (desde a Colônia) em detrimento das diversas formas de relacionamentos afetivos e sexuais das variadas etnias (indígenas e afrodescendentes) que compuseram nossa formação histórica e que foram obliteradas e desvalorizadas. Daí a importância da produção científica crítica e decolonial brasileira sobre famílias, sexualidades, gêneros e etnias.
} 
tradicionais de formação das parcerias - os relacionamentos monogâmicos - como na obtenção dos prazeres sexuais femininos - por exemplo, a antecipação das práticas sexuais e a ampliação do repertório sexual feminino. Giddens (1993) designou esse conjunto de modificações que deram maior visibilidade e forneceram outros significados aos regimes de formações de parcerias não duradouros ou não monogâmicos de sexualidades plásticas (isto é, moldáveis, em contraposição aos formatos tradicionais e moralmente conservadores monogâmicos) ou, de maneira mais genérica, de transformações da intimidade.

Neste contexto, segundo Illouz (2019) o casamento monogâmico heterossexual - com sua longa tradição de arranjos familiares - começou a ser questionado como sendo a única possibilidade e garantia de satisfação amorosa e sexual, e progressivamente foi substituído pela valorização das escolhas particulares dos interessados na formação das parcerias. Assim, marcas da contemporaneidade são as coexistências entre modelos tradicionais de relacionamentos monogâmicos com modelos não tradicionais que enfatizam a liberdade pessoal, o questionamento do amor romântico, os relacionamentos monogâmicos e a família nuclear, a visibilidade das orientações não heterossexuais e a rotatividade e a variedade de parceiros. Estes modelos não tradicionais recebem diversas designações, tais como relacionamentos abertos, poliamorosos/poliafetivos ou relações sexuais casuais que, apesar de suas particularidades, têm como característica comum o questionamento dos relacionamentos monogâmicos tradicionais (COSTA; BELMINO, 2017; PEREZ; PALMA, 2018).

Segundo Bauman (2004), os relacionamentos afetivos e sexuais não monogâmicos ou não tradicionais são emblemas das transformações sociais da contemporaneidade, na qual pode ser observada tanto o crescente número de pessoas que denominam de amor mais de uma experiência afetiva quanto a frequente rotatividade de parceiros afetivos e sexuais ao longo da vida sem haver perda de qualidade e/ou importância nestas experiências.
Ainda para o autor, a fluidez e a rotatividade dos sentimentos e a possibilidade de satisfações imediatas - por exemplo, nas relações sexuais casuais ou na troca/rotatividade frequente de parceiros amorosos - não devem ser concebidas como disruptivas ou de menor valor/significado subjetivo, mas sim como resultantes das alterações pertinentes às relações de/entre gêneros que permitem a expressão e difusão de modelos e experiências afetivas e sexuais alternativos e distintos das tradicionais ou monogâmicas.

Freire e Gouveia (2017) e Oliveira Rotondano (2018) destacam que os relacionamentos amorosos e sexuais não monogâmicos envolvem uma diversidade de formatos e dinâmicas, por exemplo, as múltiplas parcerias em relacionamentos abertos (parceiros estáveis que permitem a inclusão episódica ou perene de novos parceiros), os trisais poliamorosos (termo êmico que significa a convivência entre três sujeitos, independentemente de seus sexos, gêneros e orientações sexuais) e os casamentos/relacionamentos estáveis grupais. Para Pilão (2015), os relacionamentos não monogâmicos incluem, mas não se limitam aos relacionamentos poliamorosos ou poliafetivos, pois estão assentados em características compartilhadas como a liberdade sexual, a rotatividade de parceiros e a partilha - mesmo que episódica - de afetos assentada na lealdade, confiança, respeito e não possessividade entre os envolvidos.

Alguns autores como Martin e Ribeiro (2020) e Oliveira Rotondano (2018) destacam que o principal eixo destes relacionamentos não monogâmicos é o sentimento de compersão, neologismo que designa, em contraposição ao ciúme, o sentimento de satisfação ao perceber a felicidade do parceiro/parceira se sentir concomitantemente amado ou sexualmente realizado por outros sujeitos; em outras palavras, a exclusão do individualismo e da possessividade. Todavia, para Cardoso (2017) isso não significa que os relacionamentos não monogâmicos solucionem os impasses resultantes do dispositivo (de controle) da sexualidade tal como proposto por Michel Foucault: longe de instaurar um comunitarismo afetivo e sexual 
eliminando totalmente o sentimento de ciúme e de posse dentre os parceiros, os relacionamentos não monogâmicos destacam a necessidade de enfretamento constante destes sentimentos e das suas eventuais consequências. Por isso, segundo Cardoso (2017) e Oliveira Rotondano (2016), a compersão não significa, necessariamente, a inexistência das insatisfações, tensões, contradições e conflitos entre os envolvidos, mas sim representa a tentativa de equilíbrio dinâmico e conciliação entre o individualismo e a busca pela satisfação pessoal com as demandas, necessidades e desejos dos parceiros visando a satisfação amorosa e sexual dos envolvidos ${ }^{4}$.

Costa e Ribeiro-Gonçalves (2020) argumentam que reconhecer que os relacionamentos não monogâmicos consensuais em seus diversos formatos participam de um movimento contemporâneo de profundas alterações nas relações afetivas e sexuais - as supracitadas transformações da intimidade - não significa pari passu sua aceitação e ou tolerância pelo conjunto da sociedade. Não à toa, devido às características tradicionais, patriarcais, misóginas e trans-homofóbicas de ampla parcela da sociedade brasileira, cujo histórico privilegiou a mononormatividade e os relacionamentos heterossexuais monogâmicos, foram perpetrados e replicados diversos preconceitos, discriminações e violências contra aqueles que não se adequavam/ adéquam a esse modelo (BALIEIRO, 2018). Por isso, Porto (2018) e Santos e Monteiro (2020) destacam a urgência de discutir as condições de uma cidadania sexual e afetiva não mononormativa que permita a inclusão e o reconhecimento destes sujeitos como detentores de plenos direitos. Em outras palavras, é preciso destacar que os relacionamentos não monogâmicos colocam em evidência o consentimento e a autonomia de decisão
- fundamentos do estado de direito - dos sujeitos em suas vivências íntimas, afetivas, amorosas e sexuais (FERNANDES, 2020).

Compreender como os sujeitos vivem seus relacionamentos não monogâmicos corresponde a uma tentativa de entender o posicionamento social e subjetivo de parcela da população que não corresponde aos modelos tradicionais monogâmicos e/ou heteronormativos de relacionamentos amorosos e sexuais, principalmente quando esses sujeitos são mulheres, haja vista as desigualdades decorrentes do duplo padrão ou dupla moral sexual ${ }^{5}$ (COSTA; BELMINO, 2015; COSTA; BELMINO, 2017; WAHBA; SIMÃO, 2020). Assim, o objetivo desta pesquisa é compreender relatos de mulheres que vivenciam ou vivenciaram relacionamentos amorosos e sexuais não monogâmicos.

\section{Aspectos metodológicos}

\section{Tipo de estudo}

Trata-se de uma pesquisa qualitativa, exploratória e transversal.

\section{Participantes}

Participaram desta pesquisa dez mulheres com idades entre 20 e 34 anos que tiveram ou que estavam no momento da coleta dos dados em relacionamentos amorosos e sexuais autodesignados como não monogâmicos - podendo ser relacionamentos abertos, casamentos abertos, trisal poliamoroso/poliafetivo ou outro. O número de participantes foi definido de acordo com o critério de saturação dos dados (FONTANELLA; RICAS; TURATO, 2008). As principais características das participantes constam na Tabela 1.

\footnotetext{
${ }^{4}$ Não à toa, Cardoso (2017, p. 12) se refere aos relacionamentos não monogâmicos como manifestações hodiernas da “estrutura [ideológica] neoliberal de subjetivação" ou - retomando Anthony Giddens - como "soluções biográficas para contradições sistêmicas" (CARDOSO, (2017, p. 16). Em outras palavras: como conciliar a longa tradição das normatizações monogâmicas e sua exclusividade sexual e afetiva com o incentivo às possibilidades de ampliação/variabilidade dos prazeres/parceiros sexuais?

${ }^{5} \mathrm{O}$ duplo padrão ou dupla moral sexual significa que historicamente nas sociedades tradicionais - inclusive na de tradição europeia cristã - é permitido aos homens experiências sexuais precoces, pré-matrimoniais e com várias parceiras, enquanto as experiências sexuais femininas são controladas e relacionadas à esfera do casamento.
} 
Tabela 1 - Caracterização das participantes.

\begin{tabular}{|c|c|c|c|c|c|c|c|}
\hline $\begin{array}{l}\text { Nome } \\
\text { fictício }\end{array}$ & Idade & Gênero & $\begin{array}{l}\text { Orientação } \\
\text { sexual }\end{array}$ & $\begin{array}{l}\text { Relacionamento } \\
\text { não monogâmico }\end{array}$ & Escolaridade & Raça/etnia & $\begin{array}{c}\text { Nível } \\
\text { socioeconômico }\end{array}$ \\
\hline Gabriela & 34 & Feminino & Bissexual & $\begin{array}{l}\text { Casamento } \\
\text { aberto }^{1}\end{array}$ & Superior & Negra & Média baixa \\
\hline Mariana & 34 & Feminino & Heterossexual & $\begin{array}{l}\text { Relacionamento } \\
\text { aberto }^{2}\end{array}$ & Mestrado & Branca & Média baixa \\
\hline Carolina & 20 & Feminino & Bissexual & Trisal $^{3}$ & $\begin{array}{l}\text { Superior } \\
\text { incompleto }\end{array}$ & Branca & Média alta \\
\hline Tatiana & 27 & Feminino & Homossexual & $\begin{array}{l}\text { Relacionamento } \\
\text { aberto }\end{array}$ & Superior & Branca & Média alta \\
\hline Yara & 20 & Feminino & Bissexual & Trisal & $\begin{array}{l}\text { Superior } \\
\text { incompleto }\end{array}$ & Branca & Média \\
\hline Beatriz & 24 & Feminino & Homossexual & $\begin{array}{l}\text { Relacionamento } \\
\text { aberto }\end{array}$ & Superior & Branca & Média \\
\hline Luíza & 23 & Feminino & Homossexual & $\begin{array}{l}\text { Relacionamento } \\
\text { aberto }\end{array}$ & $\begin{array}{l}\text { Superior } \\
\text { incompleto }\end{array}$ & Parda & Média baixa \\
\hline Clarice & 30 & Feminino & Homossexual & $\begin{array}{l}\text { Relacionamento } \\
\text { aberto }\end{array}$ & Mestranda & Branca & Média \\
\hline Laura & 20 & Feminino & Heterossexual & $\begin{array}{l}\text { Relacionamento } \\
\text { aberto }\end{array}$ & $\begin{array}{l}\text { Superior } \\
\text { incompleto }\end{array}$ & Branca & Média \\
\hline Bianca & 32 & Feminino & Heterossexual & $\begin{array}{l}\text { Relacionamento } \\
\text { aberto }\end{array}$ & Doutoranda & Branca & Média \\
\hline
\end{tabular}

Legenda: (1) casamento aberto significa que os parceiros são casados de maneira formal (civil ou religiosamente) e a seu critério podem se relacionar amorosa e sexualmente com outros parceiros; (2) relacionamento aberto significa que os parceiros não são casados de maneira formal, mas possuem uniões de caráter estável e a seu critério podem se relacionar amorosa e sexualmente com outros parceiros; (3) trisal poliamoroso/poliafetivo significa que são três os parceiros de uma relação com características de estabilidade mas que, não necessariamente, mantêm relacionamentos apenas entre si.

Fonte: os autores.

Instrumentos

Foram realizadas entrevistas semiestruturadas (TURATO, 2005) pautadas em um roteiro de perguntas formulado pelos pesquisadores que continha questões relativas à caracterização das participantes (nome, idade, gênero, orientação sexual, escolaridade, cor/raça/etnia e nível socioeconômico) e sobre temas relacionados às suas experiências em relacionamentos amorosos e sexuais não monogâmicos.

\section{Procedimentos de coleta de dados}

$\mathrm{O}$ recrutamento das participantes ocorreu a partir da estratégia de coleta de dados snowball sampling (bola de neve ou cadeia referenciada) (VINUTO, 2014), ou seja, um participante (semente) indica outros possíveis participantes (nodos) para a pesquisa. Neste caso, a semente foi contatada a partir da rede de contato pessoais dos pesquisadores, sendo que a partir dela outras quatro possíveis participantes foram indicadas e 
entrevistadas. Quando as indicações cessaram os pesquisadores contataram o grupo "Problemas de não-mono" de uma rede social da internet a partir do qual participaram outras cinco mulheres. Para o recrutamento e seleção de participantes foram estabelecidos critérios de inclusão (maiores de 18 anos de idade; identificar-se como pertencente ao gênero feminino; ter pelo menos uma experiência em relacionamento amoroso e sexual não monogâmico de qualquer tipo). Devido às recomendações de distanciamento social decorrentes da pandemia de Covid 19 (AQUINO et al., 2020) as entrevistas foram realizadas à distância com auxílio de aplicativos (Google Meet ou Zoom) que permitem a vídeogravação das entrevistas. $\mathrm{O}$ assentimento de participação e de autorização para a gravação audiovisual das entrevistas ocorreu por meio de registro sonoro. As entrevistas ocorreram entre os meses de julho e setembro de 2020 .

\section{Procedimentos de análise dos dados}

As entrevistas foram organizadas de acordo com uma análise de conteúdo temática de critérios semânticos, isto é, em categorias de conjunto de sentidos assemelhados (BARBOSA; SILVA; NUNES, 2017; BRAUN; CLARKE, 2006; SILVA; BORGES, 2017) analisados a partir de literatura científica pertinente à área.

\section{Disposições éticas}

Esta pesquisa é parte integrante do projeto Discursividades Contemporâneas Sobre Sexualidade e Gênero, aprovado pelo CEP/UFTM (CAAE 32373520.1.0000.5154 na Plataforma Brasil).

\section{Resultados e discussão}

Os dados foram organizados em três categorias. A primeira (Vivência dos afetos em relacionamentos não monogâmicos) discorreu sobre como estavam organizados e se expressavam os sentimentos e experimentações em relação à não monogamia. A segunda (Mulheres e os desafios da não monogamia) discorreu sobre as consequências dos relacionamentos não monogâmicos para as participantes. E a terceira categoria (Comunicação e expressão dos sentimentos) discorreu sobre a importância da comunicação e do sentimento de amor para os relacionamentos.

\section{Categoria 1 - Vivência dos afetos em relacionamentos não monogâmicos}

Vivenciar e experimentar afetos, modelos e dinâmicas de relacionamentos amorosos e sexuais de maneira não monogâmica foi um argumento amplamente relatado pelas participantes. Por exemplo, Beatriz descreveu este tipo de relacionamento das seguintes maneiras:

\section{[...] acho que em um relacionamento não mo- nogâmico você é livre para estar e vivenciar outras histórias sem que isso prejudique o que você vive e sente com aquela pessoa.}

E ainda:

[...] essa questão da liberdade mesmo, você pode sentir de forma diferente e não se punir, nem se culpar por conta disso.

Outra participante, Laura, afirmou que:

[...] acho que é bem aquele clichê mesmo de que se você ama, você deixa a pessoa livre.

As participantes relataram que a liberdade de viver e experienciar relacionamentos amorosos e sexuais não monogâmicos não faz soçobrar os sentimentos que possuem pelos parceiros ou parceiras em seus relacionamentos, tal como destacou Yara:

Estar com outras pessoas não muda o que a gente sente um pelo outro, é mais um envolvimento. Assim como você desenvolve uma

\footnotetext{
${ }^{6}$ Trata-se de um grupo brasileiro na rede social Facebook que possui aproximadamente 5,4 mil membros que se autodeclaram não monogâmicos.
} 
amizade com alguém, a gente só vê como um tipo de relação que não é porque você tem uma que não teria a outra.

Sobre esse mesmo aspecto outra participante, Beatriz, relatou:

[...] o sentimento permanece o mesmo, na maioria das vezes a gente fortalece o sentimento, e fortalece muito, tipo nas conversas, nas trocas de ideia de reflexão, de parceria... é muito legal.

Esses relatos sobre como as participantes experienciavam o sentimento de amor em relacionamentos não monogâmicos - ou seja, ter que dividir as atenções e os interesses entre múltiplos parceiros - foi relatado pelas participantes quando comentaram sobre suas vivências afetivas. Por exemplo, Mariana relatou que:

Por mais que os acordos são válidos e possíveis $o$ afeto pode não caber no acordo. Posso combinar com a pessoa X que só vou ficar com ela, mas não consigo combinar que afetivamente não vou me envolver com outras pessoas.

A participante Carolina respondeu que é possível amar mais de uma pessoa ao mesmo tempo:

[...] eles acham que se amasse a primeira você não amaria a segunda, mas não é assim. Eu falo que é muito amor no coração e você precisa distribuir [risos].

O conjunto destes relatos é significativo porque historicamente - a partir da tradição europeia cristã - quando o sentimento de amor passou a ser considerado um dos pilares fundamentais da consagração da união (casamento ou união livre consensual e estável) as expectativas dos envolvidos sobre a vida a dois ficaram mais difíceis de serem satisfeitas, pois esperava-se que o amor e o desejo sexual permanecessem estáveis e exclusivos por toda a vida (ILLOUZ, 2012; 2019) - o que pode não acontecer na realidade de todos os relacionamentos. Uma alternativa a essas queixas e conflitos seria reconhecer que, talvez, os modelos tradicionais monogâmicos e exclusivistas de relacionamentos amorosos e sexuais não respondem às expectativas de todos os sujeitos (LINS, 2017), reforçando a importância e a necessidade de se considerar os aspectos pertinentes à cidadania sexual e afetiva não mononormativa (PORTO, 2018).

Por isso, autores como Illouz (2019), Priore (2006) e Oliveira Rotondano (2016) argumentam que o sentimento de amor concebido como uma dádiva universal de completude e reservada somente àqueles que o experienciam em relacionamentos monogâmicos seria mais uma construção idealizada típica da ocidentalidade europeia cristã do que uma realidade observável em todos os agrupamentos sociais. Priore (2006) e Muller e Besing (2018), por exemplo, discorrem que no Brasil Colônia (séculos XVI-XIX) o discurso oficial decorrente das influências da Igreja Católica era o de que o verdadeiro sentimento de amor estaria reservado apenas aos sujeitos efetivamente casados (portanto, reconhecidos pelas autoridades religiosas), isto é, em relacionamentos monogâmicos - pois os relacionamentos não monogâmicos ou as uniões monogâmicas estáveis porém não oficializadas eram consideradas desviantes e punidas. Todavia, se nos relacionamentos monogâmicos o sentimento de amor era estimulado como emblema do vínculo entre o casal, porém, ele não era considerado necessário para fundamentar ou manter os relacionamentos - pois a função do casamento monogâmico era a geração de descendentes numa perspectiva patrilinear e patriarcal, e não a satisfação das expectativas afetivas individuais - e, assim, não à toa a sexualidade feminina era fortemente reprimida e controlada.

Contudo, a história do sentimento de amor e da formação dos casais e das famílias não é universal para o conjunto populacional - apesar das tentativas de estabilizações e de controles pretendidos por alguns grupos de interesses - nem tampouco esteve imune às mudanças sociais. Isso pode ser visto em algumas mudanças ocorridas no Brasil República (final do século XIX). Priore (2006) em seu estudo sobre o sentimento do amor no Brasil argumenta que nas classes abastadas (com bens a serem transmitidos via herança aos filhos 
legítimos) o casamento monogâmico validado por autoridades civis ou religiosas continuava a ser obrigatório - não raro constrangendo as escolhas de parceiros mediante arranjos econômicos e/ou políticos que dispensavam a existência prévia do sentimento de amor entre os interessados. No entanto, para as classes menos abastadas das populações urbanas, a lógica das uniões e da formação das parcerias e das famílias era outra: com poucos ou sem bens a serem transmitidos via herança, o casamento oficializado ou as uniões livres ${ }^{7}$ (ambos monogâmicos) privilegiavam os sentimentos amorosos e os interesses afetivos entre os parceiros do que decorreu maior volatilidade porque estavam baseados na afetividade e nos interesses individuais. Porém, somente os casamentos monogâmicos (geralmente reservados às classes abastadas e brancas) eram social e moralmente reconhecidos por serem considerados estáveis e indissolúveis - a despeito das satisfações individuais - ao passo que os relacionamentos monogâmicos sem casamento, ou os relacionamentos não monogâmicos mais frequentes nas camadas empobrecidas (e menos brancas) eram pouco reconhecidos ou menos valorizados como moralmente adequados devido à sua volatilidade. Mas, ainda segundo Priore (2006), tanto devido à maior visibilidade da formação e estabilidade das parceiras e dos relacionamentos nas classes urbanas menos abastadas quanto devido às incipientes movimentações feministas que prezavam pela autonomia feminina, o sentimento de amor prévio entre os parceiros passou a ser amplamente valorizado frente às pressões familiares.

Essas mudanças provocaram significativas rupturas nos padrões idealizados de gênero, de família e de conjugalidade no Brasil contemporâneo e foram incentivadas nas décadas pós-meados do século XX na ocidentalidade por diversos movimentos de contracultura que prezavam pela desconstrução do ciúme, do ideal do amor romântico e pela defesa do uso livre e autônomo do corpo pelos homens e mulheres (FREIRE; GOUVEIA, 2017).
Assim, o amor livre - que inspirou o poliamor ou a poliafetividade - foi contraposto ao sentimento de exclusividade do amor romântico e, consequentemente, à família nuclear burguesa constituída a partir do casamento monogâmico e heterossexual estável e indissolúvel (FREIRE, 2013; ILLOUZ, 2019; JUNIOR, 2018).

Neste ínterim, outro elemento mencionado pelas participantes durante as entrevistas foi a liberdade de se viver concomitantemente múltiplas relações amorosas e sexuais em contraposição à monogamia. A participante Gabriela relatou que de acordo com sua experiência a monogamia tende a restringir as pessoas de forma que só seja possível "se permitir" exclusivamente com o parceiro e vice-versa; e, complementando sua resposta ela relatou que há muitas pessoas com quem pode, ao mesmo tempo, realizar trocas afetivas e sexuais. Outra participante, Mariana, respondeu que em relacionamentos monogâmicos não é possível manter simultaneamente múltiplas relações amorosas e sexuais com várias pessoas, pois a prioridade é a "entidade casal". Dessa forma, as expectativas não monogâmicas possuem mais espaço de criação - "nada é óbvio", segundo ela.

Considerando o exposto, as participantes apresentaram experiências similares às relatadas por Lemos (1994) que em sua pesquisa discorreu sobre o fato de que os sujeitos possuem necessidades afetivas e sexuais que talvez uma única pessoa/parceiro afetivo e sexual possa não satisfazer, sendo possível ou deixar essas necessidades/ desejos de lado - e mesmo assim viver razoavelmente bem - ou vivenciar relacionamentos e experiências múltiplas. Porém, segundo o autor, o que geralmente ocorre é que os envolvidos em um relacionamento monogâmico amoroso e sexual estável podem se afastar dos amigos ou deixar de fazer atividades prazerosas devido às prédicas de exclusividade com o parceiro. Em contraposição, quando há espaço para que haja outras pessoas na vida afetiva e sexual de um sujeito, isto é, em

\footnotetext{
${ }_{7}$ Segundo Priore (2006), as classes empobrecidas promoviam parcerias mais frequentemente por meio das uniões livres do que pelos casamentos segundo uma lógica simples: o casamento (civil e religioso) requeria pagamentos de taxas e emolumentos.
} 
relacionamentos não monogâmicos, o outro/parceiro pode se sentir excluído ou traído devido à crença de que (apenas) os dois se completam (LINS, 2017).

A partir desses aspectos dos relacionamentos não monogâmicos podem decorrer sentimentos contraditórios como os descritos pelas participantes ao relatarem não se enquadrar nos moldes dos sentimentos amorosos idealizados e designados como românticos. Sobre isso Yara relatou:

Eu sentia muita culpa por ter atração por outras pessoas, acabei terminando um relacionamento por causa disso, não entendia o que havia de errado comigo. Foi depois de alguns meses que eu entendi que não queria estar com uma pessoa só.

Por sua vez Clarice relatou ser natural sentir desejos sexuais e afetos/amor por mais de uma pessoa ao mesmo tempo, e que é preciso entender que há outras relações amorosas e sexuais na vida para além de uma única pessoa para todo o sempre. Gabriela relatou que os seres humanos são complexos, repletos de vontades e desejos e que nem sempre uma pessoa apenas vai suprir todas as necessidades da outra e, por isso, é importante para ela se permitir conhecer e se relacionar com outras pessoas ao mesmo tempo. Como já referido, o contrário destes relatos é que historicamente o sentimento de amor romântico na monogamia pretende ser exclusivista (ILLOUZ, 2012; LINS, 2017). Além disso, segundo Costa e Ribeiro-Gonçalves (2020) e Oliveira Rotondano (2016), para parte significativa dos sujeitos em nossa sociedade o que vigora e é aceito como moralmente adequado ou correto nos discursos dominantes é a monogamia e a heteronormatividade, segundo os quais o desejo sexual e os afetos amorosos são considerados interrelacionados e destinados apenas a uma pessoa pelo menos, para uma pessoa por vez - impossibilitando a diversificação e tendo de se escolher um parceiro para dedicar tempo e afeto.

Por fim, os afetos amorosos e os interesses sexuais quando partilhados ao mesmo tempo entre vários parceiros não raro são tidos como infidelidade, traição e derrisão da moral (PORTO, 2018).
Ademais e ainda neste sentido, Costa e RibeiroGonçalves (2020) e Kessler (2013) reforçam que devido ao duplo padrão ou à dupla moral sexual essa crítica é referida majoritariamente às mulheres, visto que para os homens a multiplicidade de parcerias amorosas e sexuais desatreladas do casamento e da monogamia pode ser "perdoada" e incentivada. Por isso, é preciso compreender as dificuldades relativas ao gênero feminino nos relacionamentos afetivos e sexuais não monogâmicos - o que nos conduz à próxima categoria.

\section{Categoria 2 - Mulheres e os desafios da não monogamia}

Um aspecto recorrente nas respostas das participantes foi a diferença entre seus relacionamentos não monogâmicos amorosos e sexuais quando comparadas aos homens - especialmente no que se refere à repressão sexual. Isso pode ser observado na resposta de Mariana:

Quando é um homem acho que é muito melhor visto [...] então, perante a sociedade ainda acho que tem aquela coisa desigual de no relacionamento não monogâmico tem muito mais preconceito: se a mulher pega [se relaciona] vários [parceiros] ela não serve para se relacionar ou casar... Mulheres acabam sofrendo mais.

Mariana relatou que as mulheres são mais cobradas moral e socialmente do que os homens no que diz respeito à sexualidade e que quando as mulheres estão em relacionamentos amorosos e sexuais não monogâmicos são rotuladas como promíscuas. A depreciação das mulheres decorrente do machismo foi comentada pelas participantes, por exemplo, em relação à multiplicidade de parceiros Yara respondeu que:

[...] para o meu namorado as pessoas falam tipo 'parabéns', 'como ele chegou nesse nível'- por ele ter duas namoradas. Para mim é como se eu precisasse de mais. 
Mediante o exposto as participantes relataram conteúdos similares aos tratados por Junior (2018) em sua pesquisa etnográfica sobre relacionamentos não monogâmicos. $\mathrm{O}$ autor argumenta que devido aos estímulos e valorizações em nossa sociedade da monogamia e/ou da conjugalidade heterossexual, os relacionamentos amorosos e sexuais não monogâmicos não são valorizados e são depreciados, apesar de também serem performances possíveis da sexualidade humana. Além disso, Costa e Ribeiro-Gonçalves (2020), Júnior (2018) e Wahba e Simão (2020) referem que a maior ou a menor depreciação destes relacionamentos não monogâmicos dependeria do gênero dos sujeitos, isto é, as mulheres são alvos de mais reprovações do que os homens, delineando condições de existência e possibilidades de agenciamentos afetivos e sexuais diferenciais para homens e mulheres. Este fato anteriormente mencionado pode ser observado na recorrência dos preconceitos dirigidos às participantes que têm múltiplas parceiras em relacionamentos abertos ou casuais e suas referências ao que ocorre com os homens em condições similares (que são valorizados), o que faz com que os relacionamentos amorosos e sexuais não monogâmicos se tornem mais dificultosos para as mulheres.

Essas diferenças entre os gêneros seriam justificadas pelo fato de a castidade e o resguardo sexual e moral das mulheres terem sido elementos cultura e historicamente incentivados nas sociedades monogâmicas e patriarcais de tradição europeia cristã, tal como a brasileira (KNIBIEHLER, 2016; PINSKY, 2016). Assim, o controle da sexualidade feminina e sua "pureza" física e moral foram valorizados para garantir a legitimidade da prole - ou seja, para garantir filhos legítimos que seriam os herdeiros do patrimônio de seu marido. A preponderância da virgindade e da honradez física e moral femininas começaram a ser questionadas de maneira mais sistemática por parte das mulheres a partir do século XX devido aos avanços científicos, à laicização da sociedade, aos movimentos feministas e ao surgimento de práticas contraceptivas medicamentosas (ILLOUZ, 2019; MULLER; BESING, 2018; PINSKY, 2016).
Tal como comentado pelas participantes, em decorrência da constante vigilância dos corpos e da sexualidade feminina, as afetividades foram prioritariamente direcionadas ao modelo do casal monogâmico estável e indissolúvel e da família nuclear heterossexual. Isso fez e ainda faz com que os sujeitos - especialmente as mulheres - em relacionamentos amorosos e sexuais não monogâmicos, sejam alvos de exclusões e, não raro, de violências. Por isso, segundo França (2017), as mulheres ainda possuem desvantagens em relação aos homens em diversos âmbitos, incluindo os relacionamentos amorosos e sexuais, já que seus comportamentos não monogâmicos e/ou não heterossexuais são mais identificados como derrisão da moral individual com consequências sociais.

Outro elemento bastante relatado nas entrevistas foi o medo ou o receio das participantes ao revelarem para outrem seus relacionamentos amorosos e sexuais não monogâmicos. Mariana relatou que:

\section{[...] a minha família nunca conseguiu entender, e no trabalho é uma coisa meio tabu, pensando na gente como mulher em alguma medida você vai ser vadia e querer dar [manter relações sexuais] para todo mundo.}

Bianca disse que:

[...] para minha família eu não contei porque acho que eles não entenderiam, eu seria muito criticada.

E, por fim, Luíza relatou que:

[...] não é um assunto que dá para falar muito.

Em suma, expor seus relacionamentos amorosos e sexuais não monogâmicos é difícil para algumas mulheres na medida em que a tendência é ser avaliada negativamente e sofrer preconceitos. Portanto, mesmo que dentre as participantes o mais comum foi não esconder suas preferências amorosas e sexuais, todavia, também foi usual e recorrente não publicizar ou comentar o assunto 
para qualquer interlocutor. Por isso, os relatos sobre os relacionamentos amorosos e sexuais não monogâmicos foram e são discutidos preferencialmente entre amigos e menos relatados para familiares e colegas de trabalho, tal como relatado por Junior (2018).

Neste sentido, os relatos de vivência do amor livre e da poliafetividade ficaram reservados a alguns contextos específicos, tal como afirmou Laura que vive um relacionamento aberto:

[...] nossas familias não sabem, a gente ficou com receio de abrir isso pra eles, então pra eles é como se fosse um relacionamento monogâmico mesmo, a gente preferiu deixar isso pra nós mesmos e pra nossos amigos.

Justamente por esse receio de ser moralmente criticada e julgada, segundo Perez e Palma (2018), as transformações potencialmente questionadoras das relações de gênero, das conjugalidades heteronormativas e dos relacionamentos monogâmicos ficam limitadas, visto que os sujeitos tendem a manter essas vivências em espaços considerados seguros para evitar preconceitos e discriminações.

Talvez não à toa o controle dos corpos em relacionamentos monogâmicos associado à posse também foi relatado pelas participantes. Por exemplo, Laura afirmou que:

[...] a questão de relacionamentos amorosos é associada muito à questão da posse, eu preciso muito dessa pessoa e ela tem que estar ali para mim o tempo inteiro, aprendi na prática que isso não é legal.

Outra participante, Gabriela, relatou que nos relacionamentos monogâmicos aquele parceiro seria apenas seu e ninguém fora do casal poderia se interessar por um dos parceiros. Por fim, Carolina relatou que:

[...] não me enquadro nessa questão de relacionamento tradicional que tem estruturas tradicionais de possessividade, além da monogamia em questão tem essa coisa da tradição da hierarquia do homem sobre a mulher.
Em outras palavras, para algumas participantes a maior parte dos relacionamentos amorosos e sexuais contemporâneos ainda opera mediante $o$ controle da sexualidade feminina por meio do modelo do casal monogâmico e heterossexual. Esse argumento coincide com o proposto por Foucault (2020) quando ele esclarece que sobre o casal incidem conjuntos estratégicos de poder que pretendem normatizá-lo - ou seja, os que não observam esse modelo de relacionamento e de formação de parcerias são considerados desviantes e sofrem punições. Ainda segundo o autor, a exclusividade de se ter apenas um parceiro (monogamia) garantiria a manutenção da instituição familiar nuclear, gerando a naturalização da posse e da propriedade privada dos corpos já que o parceiro afetivo e sexual deve ser o único e exclusivo, não permitindo - pelo menos segundo os termos legais ou moralmente adequados - relacionamentos amorosos ou sexuais com mais de uma pessoa ao mesmo tempo (poligamia).

Novamente, segundo Barbosa (2020) essa normatização e naturalização dos relacionamentos monogâmicos na tradição europeia cristã se aproximam mais das idealizações do que das práticas reais, pois elas foram e são constantemente questionadas, por exemplo, pela existência das múltiplas parcerias amorosas e sexuais por parte de jovens do sexo masculino e pelos relacionamentos extraconjugais por parte dos adultos. Assim, ambos destacam o questionamento da exclusividade do sentimento de amor romântico e da sexualidade monogâmica.

Apesar das tentativas de questionamentos dos sentimentos de posse e da exclusividade do amor por parte das participantes, o ciúme ainda reverbera nos seus relacionamentos amorosos e sexuais não monogâmicos. Isso foi exemplificado por Beatriz que relatou que os sentimentos de ciúmes, insegurança e medo de ser trocada/abandonada pelos parceiros permeiam seus relacionamentos amorosos e sexuais não monogâmicos, mas que isso ocorre devido à força das influências do ideal de amor romântico. Isso também permanece, segundo a participante, pelo fato de as pessoas não 
compreenderem que o amor é um sentimento que pode se multiplicar e dispersar sem perda qualitativa dentre vários parceiros ao mesmo tempo. Clarice reverberou esse argumento ao dizer que em seu relacionamento não monogâmico o sentimento de ciúmes sempre é acolhido ao invés de temido e, assim, ela e seus parceiros aprenderam a expressar o ciúme de maneiras menos violentas, sempre utilizando o diálogo franco e claro como estratégia de enfretamento das adversidades.

Para algumas das participantes o ciúme foi designado como sentimento que precisa ser combatido e superado por ser herança da possessividade típica dos relacionamentos monogâmicos pautados no sentimento de amor exclusivista. Mas, para outros participantes o ciúme foi relatado como um sentimento que faz parte de qualquer relacionamento amoroso e sexual, seja ele monogâmico ou não monogâmico, e que de qualquer maneira deve ser questionado e debatido entre os parceiros. Ambas as posturas - rechaço ou convívio com o ciúme - apontam para os elementos destacados por Martin e Ribeiro (2020), Pilão (2015) e Oliveira Rotondano (2016) que seriam típicos dos relacionamentos não monogâmicos: se por um lado há a ênfase na experiência do sentimento de amor compartilhado não limitado ao casal, por outro lado é preciso enfrentar o ciúme/sentimento de posse por meio do diálogo franco e aberto pretendendo o sentimento de compersão que permite a confiança, o respeito, a negociação continuada e a partilha entre os envolvidos.

Ainda sobre esse tema, alguns relatos das participantes enfatizaram a necessidade de desconstruir formas de opressão para viverem de maneira proveitosa e prazerosa seus relacionamentos amorosos e sexuais não monogâmicos, ainda mais por parte das mulheres. Clarice relatou que:

No relacionamento a gente estava tentando desconstruir várias formas de opressão: sobre nossos corpos, de domínio e da monogamia. Acho revolucionário viver uma relação assim [...] e mulheres que se desafiam a isso... acho que é muito mais desafiador por causa da nossa construção social e ideológica: a gente é mais adestrada, mais insegura... então acho que para a gente fazer isso é mais desafiador.

Por sua vez, Carolina disse acreditar que a monogamia tenha surgido de um lugar "[...] político, religioso e que tenha a ver com posse" e que as pessoas precisam entender que existem outras formas de se relacionar afetiva e sexualmente. Para a participante é bom que existam relacionamentos diferentes do "convencional" - isto é, a monogamia - para mostrar possibilidades de viver feliz "sem essa amarra, essa posse".

Portanto, em relação ao questionamento das opressões decorrentes dos relacionamentos monogâmicos e heterossexuais, Foucault (2016) esclarece que a normalização produzida pelo dispositivo da sexualidade - justamente monogâmica e heterossexual - advém de elementos históricos que correlacionam a ética e moral cristã desenvolvida ao longo dos séculos com as relações de poder próprias da modernidade. Mas, ainda na trilha do argumento do autor, devido ao seu caráter de constituição histórica, essa normalização pode ser questionada e reformulada. Por isso, o patriarcado - caracterizado pelo conjunto de normas sobre propriedade dominadas pelos homens distribuindo privilégios para e dentre os homens - vem servindo como referência à ideia de ética monogâmica e conjugal baseada na posse e dominação de um gênero (masculino) sobre o outro (feminino) (ENGELS, 2000; SAFFIOTI, 2013). Outra maneira de dizer isso é alegar que a subordinação das mulheres foi institucionalizada a partir de prédicas e atos dos quais decorreram a dependência econômica das mulheres aos homens, além da produção da divisão entre as mulheres, consideradas moralmente respeitáveis (aquelas adequadas às normas do casamento e aos ideais da "boa esposa" nos relacionamentos monogâmicos e heterossexuais) e as não respeitáveis (aquelas com atitudes contrárias à moral monogâmica estabelecida) (AZEVEDO, 2019).

Apesar de passados séculos desde a origem dessa organização social patriarcal, as mulheres ainda enfrentam as consequências dessas estruturas quando desafiam as instituições consideradas 
naturalmente morais - como a monogamia. Talvez justamente por isso Mariana complementou uma resposta ao destacar que para viver relacionamentos amorosos e sexuais não monogâmicos é importante possuir uma compreensão analítica - em termos de relações de poder - das estruturas históricas que permeiam as relações íntimas, e não as conceber somente como uma escolha individual:

Olho para a monogamia de um jeito mais amplo e político, inclusive com recortes de gênero, o que faz muita diferença. Senão a gente escorrega com facilidade para uma via liberal, de querer apenas satisfazer a minha vontade, sem responsabilidade afetiva com ninguém... porque acho que a questão é muito maior e de transformação como um todo, de estruturas sociais mesmo, muito além da vivência individual.

Destarte, a disputa pela equidade entre os gêneros e orientações sexuais se manifesta de diferentes maneiras na construção dos relacionamentos amorosos e sexuais não monogâmicos, sendo a superação do patriarcado, do machismo e da opressão feminina condições necessárias. Porém, segundo Pilão (2019), para que o questionamento e a desconstrução da monogamia sejam efetivos elas precisam atentar para as diferentes formas de opressão que incidem e produzem desigualdades na nossa sociedade e que refletem nos relacionamentos não monogâmicos. Daí a necessidade de se considerar a importância de uma cidadania plena também para aqueles que vivem relacionamentos não mononormativos (PORTO, 2018; SANTOS; MONTEIRO, 2020). Por isso, outro tema debatido pelas participantes foram as estratégias de enfrentamento das opressões/permanências de caráter tradicionalistas em seus relacionamentos amorosos e sexuais não monogâmicos - elementos abordados na próxima categoria.

\section{Categoria 3 - Comunicação e expressão}

dos sentimentos

A comunicação e o diálogo foram elementos relatados por praticamente todas as participantes como as principais e cruciais maneiras que utilizam para lidar com as vantagens e, principalmente, com as desvantagens de seus relacionamentos amorosos e sexuais não monogâmicos. Por exemplo, Yara relatou que:

Nosso principal alicerce é a comunicação. A gente entende o que tá sentindo, expõe para os dois e fala: olha, isso não me deixou confortável, fiquei com ciúme, não gostei. E aí a gente conversa para tentar entender, não necessariamente para mudar. Nunca vamos com a mentalidade de 'se eu não gostei você tem que parar', mas sim de 'por que eu não gostei? Será que realmente não foi legal? Por que eu não me sinto bem com isso?'. E assim vamos tentar fazer com que todo mundo se sinta bem.

Ainda neste sentido Bianca comentou esses aspectos ao relatar que em seu relacionamento não monogâmico em todas as ocasiões o diálogo com os parceiros era a principal ferramenta para o enfrentamento dos problemas, conflitos e adversidades. Assim, mesmo que ela e seus parceiros se ofendessem com alguma fala ou ação eles sempre dialogavam e este era um dos fundamentos da relação: sempre falar o que precisavam ou o que tinham vontade. Dessa forma e, por exemplo, Beatriz relatou que:

A gente conversa muito, resolve muitas coisas no diálogo sempre com muita honestidade. Tipo: olha aconteceu tal coisa, estou pensando em fazer tal coisa, como você se sente sobre isso? Ou: ah, me senti mal com o que aconteceu. A gente faz isso para que realmente fique algo confortável o máximo possível para todos.

Ainda sobre esse assunto, Clarice disse que a principal potencialidade de um relacionamento amoroso e sexual livre, aberto e/ou não monogâmico é o exercício do diálogo, e isso faz com que os desafios e as dificuldades dos relacionamentos valham a pena. Gabriela também disse que:

Observo o relacionamento de outras pessoas e é tudo falta de diálogo, é tudo falta de você dizer o que quer para ver se a pessoa concorda ou não. Você ter confiança de se abrir com a outra pessoa é muito importante em qualquer formato de relacionamento. 
O diálogo foi destacado como estratégia fundamental pelas participantes para evitar os desentendimentos e possibilitar que todos os envolvidos estivessem cientes de tudo que foi acordado, evitando situações de assimetria de poder entre os parceiros. O diálogo e a franqueza relatados pelas participantes como pilares dos seus relacionamentos encontra respaldo na literatura da área. Fernandes (2020), Junior (2018) e Perez e Palma (2018) argumentam que o principal objetivo dos relacionamentos amorosos e sexuais não monogâmicos - além de possibilitar outras possibilidades de desfrute das relações sexuais - é criar consenso entre os parceiros por meio do diálogo e da não possessividade, haja vista que há uma multiplicidade de parceiros envolvidos com suas necessidades, demandas e desejos. É preciso fazer concessões, ter paciência e buscar equilíbrio durante os relacionamentos, pois o principal aspecto a ser alcançado é o respeito e a responsabilidade afetiva mútua entre os envolvidos.

Portanto, segundo estes autores e também para Freire (2013) e Freire e Gouveia (2017), os relacionamentos não monogâmicos possuem pilares para seu funcionamento, a saber: lealdade, confiança, respeito, negociação e não possessividade - que só podem ser obtidos mediante o diálogo. A sinceridade, a clareza e a objetividade são fundamentais para com os parceiros no que se refere aos interesses, necessidades, afetos e desejos não somente para permitir o conhecimento e o consentimento, mas para estabelecer relacionamentos e partilhas afetivas efetivamente profundas e significativas dentre os envolvidos (JUNIOR, 2018). Por isso, Pilão (2015) e Pilão e Goldenberg (2012) argumentam que os relacionamentos amorosos e sexuais não monogâmicos não pretendem somente a variabilidade de parceiros sexuais de maneira constante ou episódica, mas intencionam principalmente a vivência afetiva do sentimento de amor de maneira esclarecida, responsável, consensual e não possessiva entre todos os envolvidos - resumidas no sentimento de compersão distinto do amor romântico e do amor paixão.
Retomando o exposto, foi bastante relatado pelas participantes suas concepções sobre o que consideram ser o sentimento de amor e como esse sentimento é vivenciado, revelando as características valorizadas e esperadas para um relacionamento adequado e satisfatório - seja ele monogâmico ou não monogâmico. Para Bianca o amor envolve respeito, diálogo e cuidado, ou seja, é conseguir se colocar no lugar do outro, entender o contexto do outro, saber das dificuldades que os parceiros enfrentam, ajudá-los em suas dificuldades e querer o bem e a satisfação de todos os envolvidos. Bianca disse ainda que para ela não seria possível qualquer relação humana sem amor, pois "amor é tudo". Outra participante, Laura, argumentou que o amor é quando se quer o bem da outra pessoa independente de qualquer coisa - "[...] é querer ver outra pessoa bem e feliz" - e desejar dar liberdade ao outro de querer estar com você não por obrigação, mas por livre decisão e escolha.

Ainda sobre este tema, Luíza destacou o respeito como importante elemento do sentimento de amor que envolve também sabedoria, acolhimento e suporte aos parceiros, além da necessidade de compreender que os parceiros são diferentes e têm suas particularidades:

[...] se eu amo uma pessoa ela pode estar em outro universo, eu amo ela independente do que acontecer, para mim amor é isso.

Beatriz complementou que para ela o sentimento de amor é poder contar com alguém e estar presente - é uma real parceria. Carolina relatou que o amor é um sentimento que se constrói durante os relacionamentos, e não um sentimento de posse que conduz à destruição das relações:

Acho que as pessoas têm meio que uma visão distorcida do amor, essa coisa do sofrimento, de correr atrás. O amor não precisa ser uma coisa dificil, eu sei que existem problemas, mas fica fácil de se resolver quando você ama a pessoa. 
Ainda para Gabriela o amor envolve cuidado para com as outras pessoas pretendendo tornálas felizes. E, por fim, Mariana afirmou que:

[...] o amor é um afeto que é muito desdobrável, muito potente, que tem várias possibilidades.

Todavia, contrariamente ao relatado pelas participantes, Priore (2006) discorre que a concepção majoritária e paradigmática na tradição europeia em relação aos relacionamentos monogâmicos é que amar corresponde a ignorar as próprias necessidades e/ou censurar os desejos de ambos os parceiros por outros. Segundo Illouz (2012; 2019) essa concepção de amor pode ser questionada nos relacionamentos amorosos e sexuais não monogâmicos: não se trata apenas de renúncia aos próprios desejos e/ou de exclusividade entre o casal, mas sim do esforço contínuo para estabelecer o sentimento de bem-estar entre todos os envolvidos independentemente dos interesses individualizados.

Para finalizar, é proveitoso destacar que em nome do amor romântico também foram justificadas inúmeras batalhas, guerras, destruições, mortes e sofrimentos. Portanto, é importante considerar as potencialidades desse sentimento diferentes das que ocorrem nos relacionamentos monogâmicos (KESSLER, 2013). O significado deste afeto pode variar de acordo com a experiência, a cultura, os valores e os sujeitos, mas quase sempre é referido como um sentimento que predispõe alguém a desejar o bem de outrem - o que permite o estabelecimento de vínculos e de laços afetivos para com uma ou mais pessoas ao mesmo tempo (REIS, 2018).

\section{Considerações finais}

Os relacionamentos amorosos e sexuais não monogâmicos são estilos e possibilidades de vivências sexuais e afetivas que coexistem com formas e modelos tradicionais - os relacionamentos monogâmicos e heterossexuais - de formação de parcerias e de famílias na nossa sociedade. Dentre os principais resultados desta pesquisa destacaramse os relacionados às transformações da intimidade, tais como: a liberdade de sentir e experienciar afetos amorosos e sexuais com mais de uma pessoa ao mesmo tempo, de maneira episódica ou perene; a possibilidade de questionar opressões de gênero e de orientações sexuais típicas dos relacionamentos monogâmicos e heteronormativos; e a importância delegada ao diálogo franco como estratégia de resolução de conflitos visando a satisfação pessoal ao perceber a felicidade dos envolvidos se sentirem concomitantemente amados ou sexualmente realizados por outros sujeitos excluindo o individualismo, o ciúme e a possessividade - o sentimento de compersão. Além destes, porém, alguns elementos referidos pelas participantes continuam relacionados às permanências dos tradicionalismos de gênero e orientações sexuais, tais como: as mulheres com múltiplos parceiros são moralmente recriminadas enquanto homens com múltiplas parceiras são valorizados; a desvalorização por parte da sociedade dos relacionamentos não-monogâmicos e/ou do poliamor/poliafetividade; e, por fim, a presença do sentimento de ciúmes.

Esta pesquisa possui alguns limites, tais como o não aprofundamento durante a análise dos dados dos aspectos interseccionais dos marcadores das desigualdades sociais das participantes - isto é, as participantes não foram comparadas segundo seus níveis socioeconômicos, raça/etnia, orientações sexuais etc. Além disso, apenas participantes mulheres foram entrevistadas, impossibilitando comparações com homens em relacionamentos não monogâmicos.

Apesar disto, esta pesquisa se mostrou relevante tanto ao problematizar aspectos tradicionais e conservadores das relações amorosas e sexuais monogâmicas quanto ao destacar modelos, dinâmicas e valores de relacionamentos não monogâmicos, possibilitando a produção e a visibilização de narrativas e práticas contrárias aos discursos hegemônicos - elementos que podem favorecer o enfrentamento das adversidades e das violências contra esses sujeitos. Ambas perspectivas destacam as tensões hodiernas nas arquiteturas das escolhas e 
das formações de parcerias no mercado afetivo e sexual, permitindo destacar os lugares de fala e os discursos dos próprios sujeitos que experienciam relacionamentos não monogâmicos na produção das suas histórias. Considerando o exposto, é importante que outras pesquisas questionadoras de relacionamentos amorosos e sexuais monogâmicos tradicionalistas sejam cada vez mais realizadas, pois apenas assim será possível problematizar as relações entre os sexos, gêneros e orientações sexuais tão desiguais em nossa sociedade.

\section{Referências}

AQUINO, E. M. L.; SILVEIRA, I. H.; PESCARINI, J. M.; AQUINO, R.; SOUZA-FILHO, J. A.; ROCHA, A. S.; VICTOR, A.; PAIXÃO, E.; MACHADO, D. B.; ALVES, F. J. A.; PILECCO, F.; TEIXEIRA, C.; FERREIRA, A.; MENEZES, G.; GABRIELLI, L.; LEITE, L.; ALMEIDA, M. C. C.; ORTELAN, N.; FERNANDES, Q. H. R. F.; ORTIZ, R. J. F.; PALMEIRA, R. N.; PINTO JUNIOR, E. P.; ARAGÃO, E.; SOUZA, L. E. P. F.; BARRAL NETTO, M.; TEIXEIRA, M. G.; BARRETO, M. L.; ICHIHARA, M. Y.; LIMA, R. T. R. S. Medidas de distanciamento social no controle da pandemia de COVID-19: potenciais impactos e desafios no Brasil. Ciência \& Saúde Coletiva, Rio de Janeiro, v. 25, supl. 1, p. 2423-2446, jun. 2020. Doi: https:// doi.org/10.1590/1413-81232020256.1.10502020

AZEVEDO, S. F. L. A ética da monogamia e o espírito do feminicídio: marxismo, patriarcado e adultério na Roma Antiga e no Brasil atual. História (São Paulo), Assis, n. 38, p. 1-19, 2019. Disponível em: https://doi.org/10.1590/1980-4369e2019053

BALIEIRO, F. F. "Não se meta com meus filhos": a construção do pânico moral da criança sob ameaça. Cadernos Pagu, Campinas, n. 53, 2018. Doi: https://doi.org/10.1590/18094449201800530006

BARBOSA, M. A. S.; SILVA, M. R.; NUNES, M. S. C. Pesquisa qualitativa no campo Estudos Organizacionais: explorando a Análise Temática. In: ENCONTRO DA ASSOCIAÇÃO NACIONAL DE PÓS-GRADUAÇÃO E PESQUISA EM ADMINISTRAÇÃO, 41., 2017, São Paulo. Anais eletrônicos [...]. São Paulo: AnPAD, 2017.
BARBOSA, M. Questões para o debate sobre a heteronormatividade nas relações afetivas: um estudo de caso sobre a rede relações livres. In: SEMINÁRIO INTERNACIONAL FAZENDO O GÊNERO, Diásporas, Diversidades, Deslocamento, 9., 2010, Florianópolis. Anais Eletrônicos [...]. Florianópolis: UFSC, 2010. p. 1-8. Disponível em: https://bit.ly/2WCu8Ja. Acesso em: 09 fev. 2021.

BAUMAN, Z. Amor líquido: sobre a fragilidade dos laços humanos. Rio de Janeiro: Zahar, 2004.

BRAUN, V.; CLARKE, V. Using thematic analysis in psychology. Qualitive Research in Psychology, London, v. 3, n. 2, p. 77-101, 2006.

CARDOSO, D. Amores plurais situados: para uma meta-narrativa socio-histórica do poliamor. Tempo da Ciência, Toledo, PR, v. 24, n. 48. p. 12-28, 2017. Disponível em: https://bit.ly/3jpoaE1. Acesso em: 4 fev. 2021.

COSTA, P. A.; RIBEIRO-GONÇAVES, J. Não monogamia consensual: atitudes de pessoas heterossexuais, homossexuais e plurissexuais. Psicologia Saúde \& Doenças, Lisboa, v. 21, n. 1, p. 104110, 2020. Doi: http://dx.doi.org/10.15309/

COSTA, T.; BELMINO, M. C. Poliamor: da institucionalização da monogamia à revolução sexual de Paul Goodman. IGT Rede, v. 12, n. 23, p. 424442, 2015. Disponível em: https://bit.ly/3mIh9QQ. Acesso em: 4 fev. 2021.

COSTA, T.; BELMINO, M. C. Poliamor: entre a institucionalização e a transgressão. Tempo da Ciência, Toledo, PR, v. 24, n. 48, p. 77-86, 2017. Doi: https://doi.org/10.48075/rtc.v24i48.18966

ENGELS, E. A origem da familia, da propriedade privada e do Estado. Rio de Janeiro: Bertrand Brasil, 2000.

FEDERICI, S. Calibã e a bruxa: mulheres, corpo e acumulação primitiva. São Paulo: Ed. Elefante, 2017.

FERNANDES, C. As porosidades do consentimento: pensando afetos e relações de intimidade. Sexualidad, Salud y Sociedad, Rio de Janeiro, n. 35, p. 165-193, 2020. Doi: https://doi.org/10.1590/19846487.sess.2020.35.09.a 
FONTANELLA, B. J. B.; RICAS, J.; TURATO, E. R. Amostragem por saturação em pesquisas qualitativas em saúde: contribuições teóricas. Caderno Saúde Pública, Rio de Janeiro, v. 24, n. 1, p. 1727, 2008. Doi: https://doi.org/10.1590/S0102311X2008000100003

FOUCAULT, M. História da sexualidade I: a vontade de saber. Rio de Janeiro: Editora Graal, 2020.

FOUCAULT, M. Subjetividade e verdade. São Paulo: Martins Fontes, 2016.

FRANÇA, M. Estigmas do poliamor: reflexões antropológicas sobre modalidades e relações nãomonogâmicas. In: SEMINÁRIO INTERNACIONAL FAZENDO O GÊNERO, 11.; WOMAN'S WORLDS CONGRESS, 13., 2017, Florianópolis. Anais Eletrônicos [...]. Florianópolis: UFSC, 2017. p. 1-13. Disponível em: https://bit.ly/3gLjiHK. Acesso em: 15 jan. 2021.

FREIRE, S. E. A. Poliamor, uma forma não exclusiva de amar: correlatos valorativos e efetivos. 2013. Tese (Doutorado) - Universidade Federal da Paraíba, João Pessoa, 2013.

FREIRE, S. E. A.; GOUVEIA, V. V. Poliamor: uma forma não convencional de amar. Tempo da Ciência, Toledo, PR, v. 24, n. 48, p. 62-76, 2017. Doi: https://doi.org/10.48075/rtc.v24i48.18965

GIDDENS, A. A transformação da intimidade: sexualidade, amor e erotismo nas sociedades modernas. São Paulo: Ed. Unesp, 1993.

ILLOUZ, E. The end of love: a sociology of negative relations. New York: Oxford University Press, 2019.

ILLOUZ, E. Why love hurts: a sociological explanation. Cambridge: Polity Press, 2012.

IOP, E. Condição da mulher como propriedade nas sociedades patriarcais. Revista Visão Global, Joaçaba, v. 12, n. 2, p. 231-250, 2009. Disponível em: https://bit.ly/2UYAth9. Acesso em: $14 \mathrm{fev}$. 2021.

JUNIOR, D. L. B. Amar é verbo, não pronome possessivo. Etnografia das relações não-monogâmicas no sul do Brasil. 2018. Tese (Doutorado) - Universidade Federal do Rio Grande do Sul, Rio Grande do Sul, 2018.
KESSLER, C. S. Novas formas de relacionamento: fim do amor romântico ou um novo amor-consumo? Sociedade e Cultura, Goiânia, v. 16, n. 2, p. 363374, 2013. Doi: https://doi.org/10.5216/sec.v16i2. 32195

KNIBIEHLER, Y. História da virgindade. São Paulo: Contexto, 2016.

LEMOS, P. Educação afetiva: por que as pessoas sofrem por amor. São Paulo: Lemos Editorial, 1994.

LÉVI-STRAUSS, C. A família. In: SPIRO, M.; LÉVI-STRAUSS, C. A familia: origem e evolução. Porto Alegre: Villa Martha Ed., 1980. p. 69-99.

LINS, R. N. Novas formas de amar. São Paulo: Ed. Planeta do Brasil, 2017.

MARTIN, C. R.; RIBEIRO, M. C. O poliamor no Brasil contemporâneo: definições, gênero, ciúme e preconceito. Revista Brasileira de Sexualidade Humana, Rio de Janeiro, v. 31, n. 2, p. 54-63, 2020. Doi: https://doi.org/10.35919/rbsh.v31i2.677

MULLER, C. M.; BESING, M. A trajetória histórica da mulher no Brasil: da submissão à cidadania. Revista Augustus, Rio de Janeiro, v. 23, n. 45, p. 25-46, 2018. Doi: https://doi.org/10.15202/1981 $896.2018 \mathrm{v} 23 \mathrm{n} 45 \mathrm{p} 25$

OLIVEIRA ROTONDANO, R. Entre monogamia e poliamor: o futuro da família no Brasil. Revista de La Facultad de Derecho, Montevidéu, n. 44, p. 1-27, 2018. Doi: http://dx.doi.org/10.22187/ rfd2018n44a10

OLIVEIRA ROTONDANO, R. Cultura e ética na formação familiar: a poligamia e sua repressão no ocidente. Revista de Bioética y Derecho, Barcelona, v. 38, p. 87-99, 2016. Doi: https://dx.doi. org/10.1344/rbd2016.38.17047

PEREZ, T. S.; PALMA, Y. A. Amar amores: o poliamor na contemporaneidade. Psicologia \& Sociedade, Rio de Janeiro, v. 30, n. 1, p. 1-11, 2018. Doi: https://doi.org/10.1590/1807-0310/ 2018v30165759

PILÃO, A. C. Entre a liberdade e a igualdade: princípios e impasses da ideologia poliamorista. Cadernos Pagu, Campinas, n. 44, p. 391-422, 2015. Doi: https://doi.org/10.1590/1809-4449201 500440391 
PILÃO, A. C. Quando o amor é o problema: feminismo e poliamor em debate. Revista Estudos Feministas, Florianópolis, v. 27, n. 3, p. 1-14, 2019. Doi: https://doi.org/10.1590/1806-95842019v27n355097

PILÃO, A. C.; GOLDENBERG, M. Poliamor e monogamia: construindo diferenças e hierarquias. Revista Ártemis, João Pessoa, v. 13, n. 1, p. 6271, 2012. Disponível em: https://bit.ly/3zzRyNp. Acesso em: 10 dez. 2020.

PINSKY, C. B. Virgindade: tema atual, tema de História. Revista Estudos Feministas, Florianópolis, v. 24, n. 3, p. 1015-1017, 2016. Doi: https://doi. org/10.1590/1806-9584-2016v24n3p1015

PORTO, D. Mononormatividade, intimidade e cidadania. Revista Direito GV, São Paulo, v. 14, n. 2, p. 654-681, 2018. Doi: https://doi.org/10.1590/23176172201825

PRIORE, M. D. História de amor no Brasil. São Paulo: Contexto, 2006.

REIS, J. B. G. Amor Plural: refletindo sobre a conjugalidade no poliamor. Revista Brasileira de Sexualidade Humana, Rio de Janeiro, v. 28, n. 2, p. 75-81, 2018. Doi: https://doi.org/10.35919/rbsh. v28i2.26

SAFFIOTI, H. I. B. A mulher na sociedade de classes: mitos e realidade. Petrópolis: Vozes, 2013.

SANTOS, T. N.; MONTEIRO, F. P. C. Poliamor: conceitos e espécies. In: CONGRESSO INTERNACIONAL DE DIREITOS HUMANOS DO CENTRO SUL DA BAHIA, 2., 2020, Vitória da Conquista. Anais [...]. Vitória da Conquista: Faculdade Santo Agostinho, 2020. p. 138-142, 2020. Disponível em: https://bit.ly/3t3W84f. Acesso em: 12 jan. 2021.

SILVA, C. C.; BORGES, F. T. Análise temática dialógica como método de análise de dados verbais em pesquisas qualitativas. Linhas Críticas, Brasília, v. 23, n. 51, p. 245-267, 2017. Doi: https:// doi.org/10.26512/lc.v23i51.8221

TURATO, E. R. Métodos qualitativos e quantitativos na área da saúde: definições, diferenças e seus objetos de pesquisa. Revista Saúde Pública, São Paulo, v. 39, n. 3, p. 507-514, 2005. Doi: https:// doi.org/10.1590/S0034-89102005000300025
VINUTO, J. A amostragem em bola de neve na pesquisa qualitativa: um debate em aberto. Temáticas, Campinas, v. 22, n. 44, p. 203-220, 2014. Doi: https://doi.org/10.20396/tematicas.v22i44.10977

WAHBA, L. L.; SIMÃO, J. B. Sexo casual: motivações, atitudes e comportamentos de homens e mulheres heterossexuais adultos. Psicologia: Ciência e Profissão, São Paulo, v. 40, p. 1-15, 2020. Doi: https://doi.org/10.1590/1982-3703003213871
Recebido em: 9 jun. 2021

Aceito em: 30 ago. 2021 
Corá, A. C. R.; De Tilio, R. 